\title{
Porta-enxertos alternativos para cultivo de laranja Valência na região sudoeste do estado de São Paulo
}

\author{
Lilian Massaro Simonetti ${ }^{1}$, Mariângela Cristofani-Yaly ${ }^{2}$, Vera Lucia Nishijima Paes de Barros ${ }^{3}$, \\ Evandro Henrique Schinor ${ }^{4}$, André Luiz Fadel ${ }^{2}$, Marília Caixeta Sousa ${ }^{5}$, Sarita Leonel ${ }^{1} \&$ \\ Marco Antonio Tecchio ${ }^{1}$
}

\section{RESUMO}

Híbridos de tangerina Sunki vs Poncirus trifoliata cv. Rubidoux são uma nova geração de porta-enxertos para a citricultura que apresentam o potencial de reunir características como, formação de plantas com menor porte de copa, elevada eficiência produtiva e produção de frutos com alta qualidade de suco. O objetivo do presente estudo foi avaliar híbridos de porta-enxertos de citros, em competição com limão 'Cravo' (Citrus limonia Osbeck), enxertados com laranja 'Valência' (Citrus sinensis (L.) Osbeck), visando novas seleções de porta-enxertos para a citricultura. Foram avaliadas 48 combinações de laranja 'Valência' com híbridos utilizados como porta-enxerto e o limão Cravo. As variáveis analisadas foram: compatibilidade entre copa e porta-enxerto, desenvolvimento vegetativo das plantas, produção, eficiência produtiva, massa dos frutos, diâmetros equatorial e polar dos frutos, rendimento do suco, teores de sólidos solúveis totais (SST - ${ }^{\circ}$ Brix), acidez titulável (AT), "ratio" (Relação SST/AT), índice tecnológico (IT). Foi calculado um índice de desempenho para cada combinação copa/porta-enxerto. Para isso, foram previamente determinados índices para as variáveis produção de frutos, rendimento de suco, "ratio" e índice tecnológico. Os resultados obtidos permitiram concluir que ao menos 18 híbridos enxertados com laranja 'Valência' mostraram melhores índices de desempenho em relação ao limão 'Cravo'.

Termos de indexação: citrandarins, Citrus, índice de desempenho.

\section{Alternative rootstocks for Valencia orange cultivation in the southwest region of the state of São Paulo}

\section{SUMMARY}

Hybrids of mandarin Sunki vs Poncirus trifoliata cv. Rubidoux are a new generation of citrus rootstocks that have potencial to bring together characteristics such as, formation of plants with lower canopy size, high productive efficiency and production of fruits with high quality of juice. The objective of the present study was to evaluate citrus rootstocks in competition with Rangpur lime

\footnotetext{
${ }^{1}$ Faculdade de Ciências Agronômicas, Universidade Estadual Paulista “Júlio de Mesquita Filho” - UNESP, Botucatu, SP, Brasil

${ }^{2}$ Centro de Citricultura Sylvio Moreira, Instituto Agronômico - IAC, Cordeirópolis, SP, Brasil

${ }^{3}$ Polo Regional Sudoeste Paulista - Capão Bonito, Agência Paulista de Tecnologia dos Agronegócios - APTA Regional, Capão Bonito, SP, Brasil

${ }^{4}$ Centro de Ciências Agrárias, Universidade Federal de São Carlos - UFSCar, Araras, SP, Brasil

5 Instituto de Biociências de Botucatu, Universidade Estadual Paulista "Júlio de Mesquita Filho" - UNESP, Botucatu, SP, Brasil 
(Citrus limonia Osbeck) grafted with 'Valencia' sweet orange [Citrus sinensis (L.) Osbeck], aiming at new rootstocks selections for citriculture. We evaluated 48 combinations of 'Valencia' sweet orange with hybrids used as rootstock and Rangpur lime. The variables analyzed were: scion and rootstock compatibility, plant growth, yield, fruit mass, equatorial and polar fruit diameters, juice yield, total soluble solids content (SST - ${ }^{\circ}$ Brix), Titratable acidity (AT), ratio (SST/AT ratio) and technological index (IT). A performance index was calculated for each canopy / rootstock combination. For this, indexes were previously determined for the variables fruit production, juice yield, ratio and technological index. The obtained results allowed to conclude that at least 18 hybrids grafted with 'Valencia' sweet orange showed better performance indexes in relation to Rangpur lime.

Index terms: citrandarins, Citrus, performance index.

\section{INTRODUÇÃO}

Os híbridos provenientes do cruzamento das tangerinas Sunki [Citrus sunki (Hayata) hort. ex Tan.] ou Cleópatra (C. reshni hort. ex Tan.) com Poncirus trifoliata Raf. são chamados de citrandarins, nos quais se deseja reunir as vantagens apresentadas pelas tangerinas, como menor suscetibilidade ao declínio dos citros, ao viróide da exocorte e a solos alcalinos, às do P. trifoliata, como resistência à tristeza dos citros, à gomose de Phytophthora e às baixas temperaturas, além de induzir a formação de plantas com menor vigor e, portanto, menor volume de copa (Blumer \& Pompeu Junior, 2005; Pompeu Junior \& Blumer, 2009, 2011).

A planta cítrica é constituída de copa e porta-enxerto, na maioria das vezes composta por espécies diferentes, sendo necessários estudos direcionados para o melhoramento destas espécies, como também para a interação entre elas (Machado et al., 2005). Os porta-enxertos influenciam muitas características das copas podendo-se destacar: vigor, precocidade de produção, produção, qualidade das frutas e suco, permanência das frutas na planta, conservação da fruta após a colheita, tolerância da planta à salinidade, à seca, a baixas temperaturas e a doenças. Outro fator a ser considerado é a incompatibilidade entre certas combinações de copa/porta-enxerto. Exemplos de incompatibilidades são as que ocorrem entre os porta-enxertos citrumelo 'Swingle' e o P. trifoliata com a laranja 'Pera' e o tangor 'Murcott' formando plantas pouco produtivas e de vida curta (Pompeu Junior, 2005). A enxertia viabiliza a produção em diferentes condições edafoclimáticas. Entretanto, esse processo é muitas vezes limitado pela incompatibilidade. A conexão da copa e porta-enxerto é fundamental para o crescimento vegetativo e absorção de água e de nutrientes. Os distúrbios fisiológicos induzidos por descontinuidades nos sistemas vasculares na região de união de copa e porta-enxerto podem reduzir o desenvolvimento vegetativo devido à comunicação restrita entre eles, necrose de tecidos e exsudação de goma, resultando em desenvolvimento anormal da parte aérea. Há um consenso geral de que quanto maior a distância taxonômica entre porta-enxerto e copa, menores são as chances de formação de uma união bem sucedida. Isto teoricamente significa que o sucesso de uma determinada combinação segue a seguinte ordem: intraclonal $>$ intraespecífica $>$ Intergenérica > intrafamiliar (Andrews \& Marquez, 1993). Desta forma, um programa de melhoramento visando à obtenção de novas cultivares de porta-enxertos, deve levar em consideração a compatibilidade entre estes e as cultivares copa.

Em se tratando da qualidade das frutas e suco, as principais características influenciadas pela combinação copa e porta-enxerto referem-se a: cor, espessura e conteúdo de óleo da casca; tamanho e peso dos frutos; cor e conteúdo de suco (expressa em \%); teor de sólidos solúveis totais (expresso em ${ }^{\circ}$ Brix) e acidez do suco, conteúdo de nutrientes, sais minerais e ácidos graxos do suco e conservação pós-colheita. Em determinadas regiões, algumas dessas características podem ser significativamente afetadas pela temperatura.

O suco natural integral pasteurizado pronto para consumo, ou simplesmente suco pasteurizado de laranja ("pasteurazed oranje juice" - POJ), também conhecido como "not from concentrate" (NFC), é o suco extraído da fruta e destinado ao consumo sem passar pelas etapas de concentração e posterior reconstituição. O suco NFC vem apresentando forte crescimento em mercados emergentes (CITRUSBR, 2017) e possui como característica o teor de sólidos solúveis semelhante ao da própria fruta, em torno de 11,5 "Brix e "ratio" em torno de 14,5. A produção do NFC é diferenciada desde o critério de escolha da matéria prima para a extração do suco, devendo ser proveniente somente de frutas selecionadas aptas e maduras. Um complicador no caso, é a manutenção do mesmo padrão de aparência e sabor ao longo do ano, na medida em que as frutas utilizadas para sua produção possuem diferentes estádios de maturação ao longo do período e 
diferentes variedades, além do que cada safra tem uma característica diferente da outra, sendo afetada por clima, produtividade, etc (Darros-Barbosa \& Curtolo, 2005).

Novos porta-enxertos obtidos pelo Programa de Melhoramento de Citros do Centro de Citricultura "Sylvio Moreira" estão sendo avaliados em diferentes regiões do estado de São Paulo. Esses porta-enxertos são híbridos de tangerina 'Sunki' (TS) com Poncirus trifoliata (PT). São considerados citrandarins e constituem uma nova geração de porta-enxertos que pretende reunir vantagens apresentadas pelas tangerinas, como a tolerância ao declínio, exocorte, morte súbita dos citros às dos trifoliatas como resistência à tristeza do citros, nematóides, gomose de Phytophtora, redução do volume de copa e melhor qualidade das frutas e suco.

O objetivo do presente trabalho foi selecionar citrandarins empregados como porta-enxertos para laranja 'Valência'como alternativa ao uso do limão 'Cravo', em Capão Bonito, SP.

\section{MATERIAL E MÉTODOS}

\section{Desenvolvimento da planta, produção e eficiência produtiva}

Quarenta e sete híbridos (citrandarins) provenientes do cruzamento das microtangerinas Sunki [C. sunki (Hayata) hort. ex Tan.] com Poncirus trifoliata Raf. cv 'Rubidoux' e o limão 'Cravo' (C. limonia) foram selecionados para a condução do experimento de competição. As plantas foram enxertadas com a variedade copa 'Valência' (C. sinensis Osbeck), totalizando 48 combinações de laranja 'Valência' com porta-enxertos, e o plantio foi estabelecido no espaçamento de $6,0 \mathrm{~m} \mathrm{x} 3,5 \mathrm{~m}$ com delineamento em blocos casualizados, quatro repetições e uma planta por parcela. O experimento foi instalado em dezembro de 2010, no Pólo Regional do Sudoeste Paulista, da Secretaria da Agricultura do estado de São Paulo, localizado na região do Alto Paranapanema, município de Capão Bonito, situado a $24^{\circ} 00^{\prime} 21^{\prime \prime} \mathrm{S}$ e a $48^{\circ} 20^{\prime} 58^{\prime \prime} \mathrm{O}$ e altitude $705 \mathrm{~m}$. Segundo Köppen e Geiger a classificação do clima é Cfa. A temperatura média anual em Capão Bonito é $18,8^{\circ} \mathrm{C}$. A média anual de pluviosidade é de $1.628 \mathrm{~mm}$. As avaliações foram realizadas em outubro de 2014.

A compatibilidade entre copa e porta-enxerto foi avaliada por meio da abertura de uma "janela" retangular na região de união copa/porta-enxerto, retirando-se a casca e verificando-se a presença de sintomas típicos relacionados à incompatibilidade, como a presença de pontuações, linha de goma e necrose (Schinor et al., 2013). O critério adotado foi presença ou ausência de sintomas, não se considerando a intensidade do anel de goma.

O desenvolvimento vegetativo das plantas foi avaliado através de aferições da altura e diâmetro da copa. As mensurações foram realizadas com régua graduada, efetuando-se medições paralelas ao eixo de crescimento geoposito da copa (altura) e paralelas ao solo na altura de 1,5 m (diâmetro). O volume calculado por meio da função: $V=2 / 3 \pi R^{2} H$, onde $V$ representa o volume da copa em metros cúbicos; $\mathrm{R}$, o raio da copa e $\mathrm{H}$, a altura da copa, de acordo com Schinor et al. (2013).

A avaliação da produção das plantas foi realizada pela pesagem direta de todos os frutos da parcela, e a eficiência produtiva obtida pela produção total de frutos da planta dividida pelo volume de copa.

\section{Caracteristicas físicas e químicas dos frutos}

Para as avaliações das características físico-químicas, amostras foram coletadas e encaminhadas ao Laboratório de Melhoramento e Qualidade da Fruta do Centro de Citricultura Sylvio Moreira do Instituto Agronômico (IAC):

Coleta: para a análise foram colhidos cinco frutos na porção externa da copa, na faixa compreendida entre 1,0 e $2,0 \mathrm{~m}$ de altura do solo e em toda a extensão do perímetro da planta.

Massa dos frutos: a massa total dos frutos foi obtida, de uma só vez, em uma balança marca Filizola com capacidade de $15 \mathrm{~kg}$, com sensibilidade $5 \mathrm{~g}$.

Diâmetros equatorial e polar dos frutos: as determinações foram feitas por leitura direta de cada amostra, com auxílio de uma escala graduada, em centímetros.

Rendimento de suco: foi determinado após esmagamento do fruto na extratora OIC (Organização Internacional Centenário) modelo OTTO 1800 (filtro com diâmetro interno $=26,11 \mathrm{~mm}$; comprimento $=265 \mathrm{~mm}$; furos de diâmetro $=0,6 \mathrm{~mm}$; área de vazão $=20 \%$ ) e calculado através da relação massa do suco/massa do fruto e expresso em porcentagem.

Sólidos solúveis: o teor de sólidos solúveis foi determinado por leitura direta no refratômetro B\&S, modelo RFM 330 e expresso em ${ }^{\circ}$ Brix. Os dados foram corrigidos pela temperatura e pela acidez do suco.

Acidez titulável: a acidez foi obtida por titulação de $25 \mathrm{~mL}$ de suco, com uma solução de hidróxido de sódio de normalidade 0,3125 e usando-se fenolftaleína como indicadora. 
Relação sólidos solúveis/acidez (ratio): foi calculada a relação sólidos solúveis/acidez. Essa relação indica o estádio de maturação dos frutos cítricos.

Índice tecnológico (IT): IT = (Rendimento em suco x SS x 40,8)/10.000 conforme proposto por Di Giorgi et al. (1990).

As análises estatísticas de todas as variáveis mensuradas neste estudo foram realizadas por meio do programa estatístico SISVAR (Ferreira, 2008), sendo os resultados submetidos à análise de variância e as médias agrupadas pelo teste de Scott-Knott a 5\% de probabilidade (Scott \& Knott, 1974).

Em complementação, foi calculado um índice de desempenho para cada combinação copa/porta-enxerto. Para isso, foram previamente determinados índices para as variáveis produção de frutos, rendimento de suco, "ratio" e índice tecnológico, através da equação: IV = 100*(100-x)/(max-min) onde, $\mathrm{x}$ é o valor médio da variável, max é o valor máximo da variável e min é o valor mínimo da variável, adaptado de Caputo et al. (2012). Para o cálculo do índice de desempenho da cultivar, foi utilizado a equação: $\mathrm{IC}=[(\mathrm{A} \times \mathrm{a}+\mathrm{B} \times \mathrm{b}+\mathrm{C} \times \mathrm{c}+\mathrm{D} \times \mathrm{d}+\mathrm{E} \times \mathrm{e}) /(\max -\min )]$, em que: A, B, C, D e E correspondem aos índices de cada variável escolhida; e a, b, c, d e e correspondem à importância relativa atribuída à cada variável (peso da variável) em percentagem, em que max é o valor máximo da variável, e min é o valor mínimo da variável.

Os pesos de cada variável foram atribuídos segundo sua importância relativa, de acordo com o critério: $20 \%$ para produção de frutos, $25 \%$ para rendimento em suco, $40 \%$ para "ratio" e $15 \%$ para índice tecnológico. Após, os valores médios referentes aos índices foram analisados pelo teste de normalidade de Shapiro-Wilk e comparados pelo teste não paramétrico de Friedman.

\section{RESULTADOS E DISCUSSÃO}

Todas as combinações copa e porta-enxertos mostraram-se compatíveis, sem a ocorrência de anel de goma na linha de enxertia, resultado também encontrado por Pompeu Junior \& Blumer (2011) onde nenhum dos citrandarins estudados por eles apresentou sintomas de incompatibilidade com a laranja Valência.

Para as características avaliadas, em 2014, a altura de copa variou de 1,23 m para a Valência/TSxPT 213 a 2,63 m para a Valência/TSxPT208 que não diferiu estatisticamente dos valores encontrados para a combinação Valência/limão Cravo (2,60 m) (Tabela 1).
O diâmetro da copa variou de 1,03 m para a combinação Valência/TSxPT 213 a 2,40 m para Valência/TSxPT 288. O híbrido TSxPT213 apresentou o menor volume de copa $\left(2,31 \mathrm{~m}^{3}\right)$ e as combinações Valência/TSxPT183 e Valência/TSxPT 10 apresentaram os maiores valores para volume de copa, isto é, $9,36 \mathrm{~m}^{3} \mathrm{e} 8,71 \mathrm{~m}^{3}$, respectivamente, que não diferiram estatisticamente de Valência/limão Cravo (Tabela 1).

Para a variável volume de copa maior vigor foi relacionado às combinações envolvendo os porta-enxertos TSxPT 10 e 183, as quais não diferiram da combinação com limão 'Cravo' (Tabela 1).

As combinações de Valência e híbridos de porta-enxertos que apresentaram menor volume de copa foram laranja Valência sobre os híbridos TS x PT 11, 134, 148, 157, 213, 254 e 294, com valores abaixo de $4,51 \mathrm{~m}^{3}$, podendo ser considerados como potenciais híbridos ananicantes.

Quanto à produção, as combinações de Valência sobre os diversos porta-enxertos se dividiram em dois grupos, com um grupo variando de 17,41 a $33,90 \mathrm{~kg}$ planta $^{-1}$ que envolve, por exemplo, o limão Cravo e os híbridos TSxPT 10, 12, 18, 24, 105, 154, 163, 182, 183, 208, 254, 290,303 e de 2,70 a 16,15 $\mathrm{kg}$ planta $^{-1}$ como por exemplo, os híbridos TSxPT 7, 8, 11, 21, 23, 80, 119, 134, 142, 148, 152, 155, 157, 181, 246, 248 e 302.

Para a variavel eficiência produtiva, os valores encontrados não diferiram estatisticamente. Apesar de todas as combinações terem apresentado o mesmo desempenho em relação à eficiência produtiva, pode-se destacar que as combinações enxertadas nos porta-enxertos TSxPT 10, 12, $18,24,105,119,154,163,182,183,205,208,224,244$, 254, 257, 271, 275, 285, 288, 290, 303 e limão 'Cravo' se agruparam entre as mais produtivas em kg planta-1.

Para as características massa do fruto (MF), diâmetros equatorial (DE) e polar dos frutos (DP), relação diâmetro polar e equatorial $(\mathrm{P} / \mathrm{E})$, rendimento de suco (RS em \%) e acidez titulável (AT), as combinações de laranja Valência sobre os diversos porta-enxertos também se dividiram em dois grupos de plantas que diferiram estatisticamente entre si. Para os teores de sólidos solúveis totais, o maior valor foi alcançado pela combinação Valência/TSxPT 148 (11,60 ${ }^{\circ}$ Brix). $\mathrm{O}$ trifoliata é conhecido como um porta-enxerto que induz às variedades copa frutos menores, com elevados valores de sólidos solúveis e ratio, boa coloração e maturação tardia (Stuchi et al., 1996, 2002). 


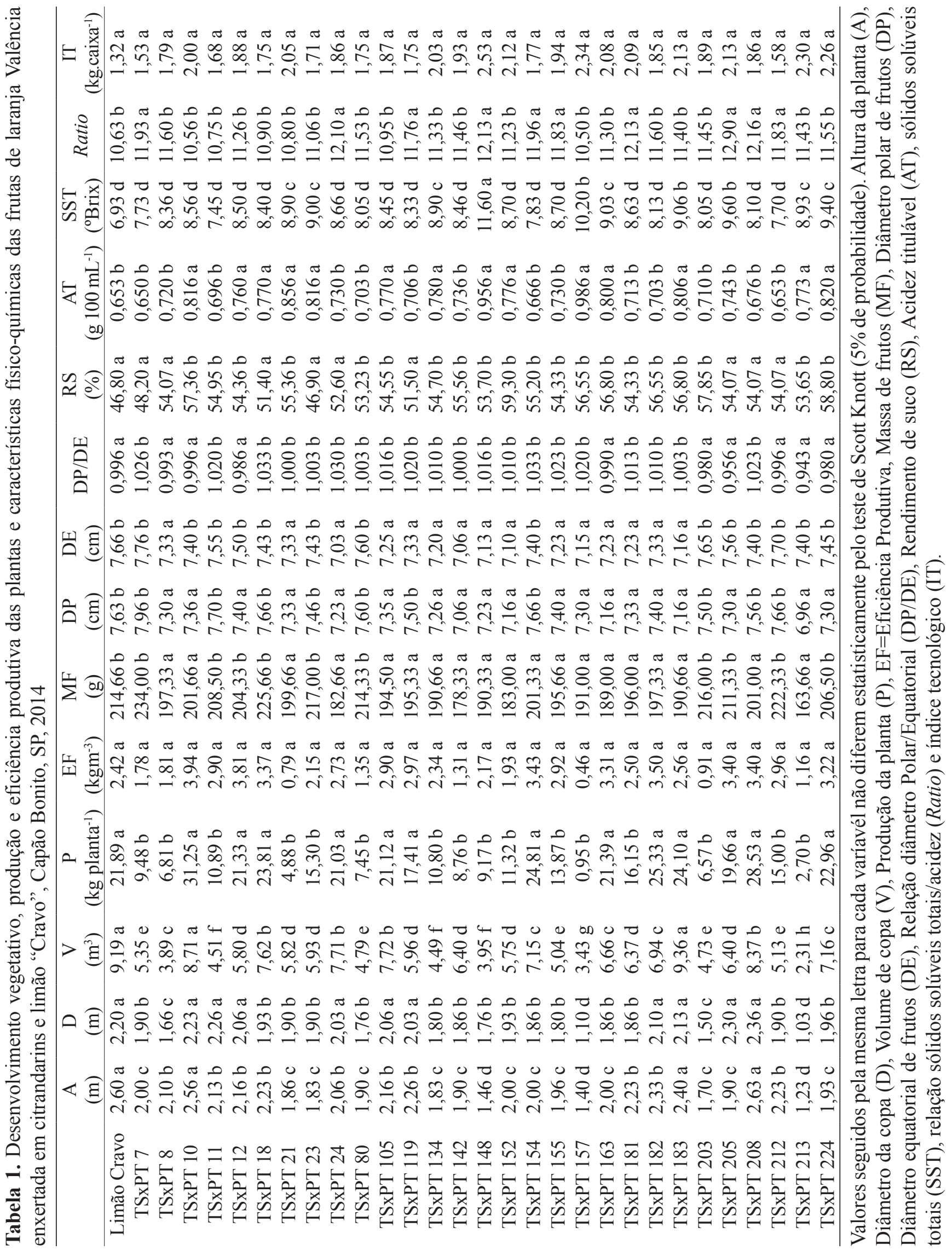




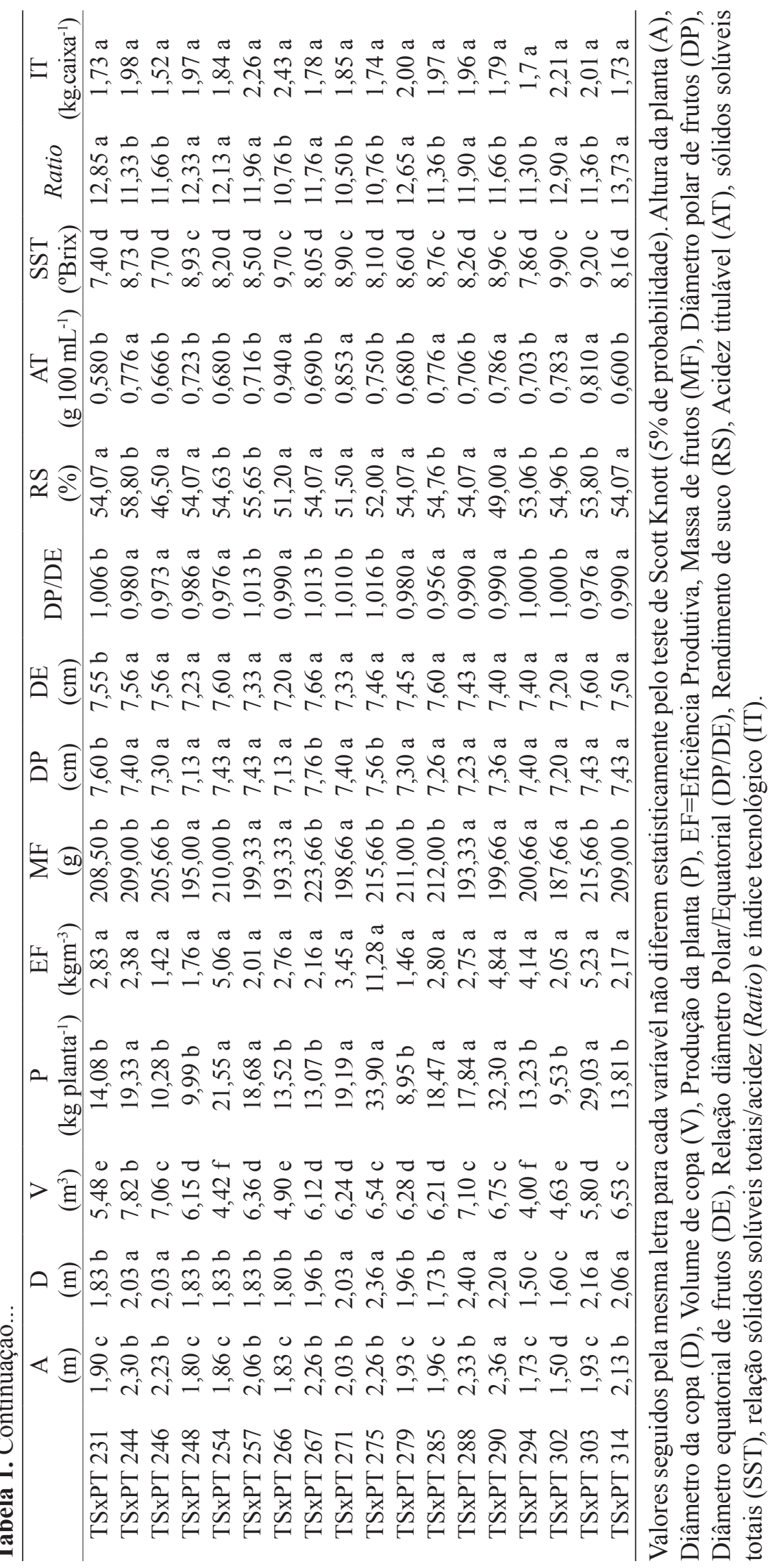


Segundo Chitarra \& Campos (1981) e Russo (1987), uma das características utilizadas para determinar a maturação dos frutos cítricos são os teores de sólidos solúveis totais ( ${ }^{\circ}$ Brix). No presente trabalho, alguns citrandarins apresentaram valores de SST superiores ao limão 'Cravo', sendo promissores pelo fato das frutas serem obtidas na região de Capão Bonito. Segundo Steger (1990), o valor de acidez apropriado para industrialização está entre 0,75 e $1 \%$. A temperatura é o fator que mais influencia no acúmulo do ácido cítrico. Após alcançar o valor máximo, o conteúdo de ácidos diminui devido ao aumento no tamanho do fruto e sua utilização no processo respiratório, que é dependente da temperatura. Quanto maior a temperatura do ambiente durante a maturação, maior o decréscimo da concentração de ácidos; Albrigo, 1992). Isso explica os valores elevados de acidez, pois na região de Capão Bonito o clima é mais ameno que nas regiões centro e norte do estado de São Paulo.

O estudo das correlações entre caracteres é muito importante, pois o melhorista tem condições de orientar a seleção de forma indireta para aqueles caracteres de interesse (Galarça et al., 2010). Os resultados (Tabela 2) demonstram a existência de correlações significativas (correlação de Pearson, para $\mathrm{p}<0,05$ ) entre várias das características físicas e químicas da planta e do suco analisados.

No presente estudo, pode-se afirmar que houve correlação positiva entre a variável alturada planta (A) e as variáveis diâmetro da copa (D), volume da copa (V), produção $(\mathrm{P})$, eficiência produtiva $(\mathrm{EF})$, massa $(\mathrm{MF}) \mathrm{e}$ diâmetro polar dos frutos (DP) e negativa entre altura de planta (A) e as variáveis rendimento de suco (RS), acidez (AT), sólidos solúveis totais (SST), "ratio" e índice tecnológico (IT). Padrão semelhante foi observado para a variável diâmetro de copa (D), porém diferentemente da variável altura de planta (A), não foram observadas correlações em relação às variáveis diâmetro polar dos frutos (AF) e "ratio" (Tabela 2).

Foram observadas ainda correlações positivas entre volume da copa $(\mathrm{P})$ e produção $(\mathrm{P})$, entre produção $(\mathrm{P})$ e as variáveis eficiência produtiva $(\mathrm{EF})$ e diâmetro polar do fruto (DP), massa dos frutos (MF) com diâmetro polar dos frutos (DP) e diâmetro equatorial dos frutos (DE), entre diâmetro polar dos frutos (DP) e as variáveis diâmetro equatorial dos frutos (DE) e relação diâmetro polar/Equatorial (DP/DE). A variável sólidos solúveis totais (SST) correlacionou-se positivamente com índice tecnológico (IT) e a variável acidez (AC) com sólidos solúveis totais (SST), índice tecnológico (IT) e negativamente com "ratio".

As variáveis massa (MF) e diâmetro polar dos frutos (DP) apresentarm correlações negativas com rendimento de suco (RS), acidez (AT), sólidos solúveis totais (SST) e índice tecnológico (IT). O mesmo foi observado para diâmetro equatorial dos frutos (DE), com exceção à correlação com a variável rendimento de suco (RS). As correlações negativas de MF, DP e DE com AT pode ser explicada pela diminuição da acidez no fruto ocorrer em função da diluição, pela expansão do fruto e aumento na concentração de água (Medina et al., 2005; Kimball, 1984).

Correlações aqui apresentadas entre $\mathrm{P}$ e EF, MF e DE e entre AT e "ratio" também foram reportadas por Legua et al. (2011) e Fadel (2015) em estudos envolvendo cultivo de laranja doce em diferentes porta-enxertos.

Para o processamento industrial, embora a boa aparência dos frutos seja desejável, o rendimento do suco, sua cor, o "ratio" e o índice tecnológico - sólidos solúveis totais no suco, em caixa de 40,8 kg (\%suco x SST x 40,8 x 10.000-1) - são consideradas as variáveis mais importantes a serem consideradas (Caputo et al., 2012).

Em relação ao índice de desempenho, nenhum dos híbridos mostrou-se inferior ao limão 'Cravo'. As combinações envolvendo a laranja Valência e os híbridos TSxPT 205, 257, 314, 302, 181, 231, 224, 208, 279, 148, 183, 288, $254,154,248,24,303$ e 163 apresentaram melhores desempenhos, diferindo estatisticamente da combinação com limão 'Cravo' (Figura 1).

Em estudo anterior, esse índice mostrou-se eficiente para seleção de cultivares de laranja doce, tanto para aptidão industrial quanto para consumo in natura (Caputo et al., 2012). Índices semelhantes baseados em características fenotípicas, já foram utilizados para seleções em outras culturas (Dovale et al., 2011; Ferreira et al., 2005).

Os resultados aqui apresentados, em relação ao desempenho das diferentes combinações copa/portaenxerto, mostraram que algumas das combinações envolvendo citrandarins possuem potencial para cultivo de laranja 'Valência' na região sudoeste do estado de São Paulo, como alternativa ao uso do limão 'Cravo'. A Figura 2 mostra alguns destes híbridos. 


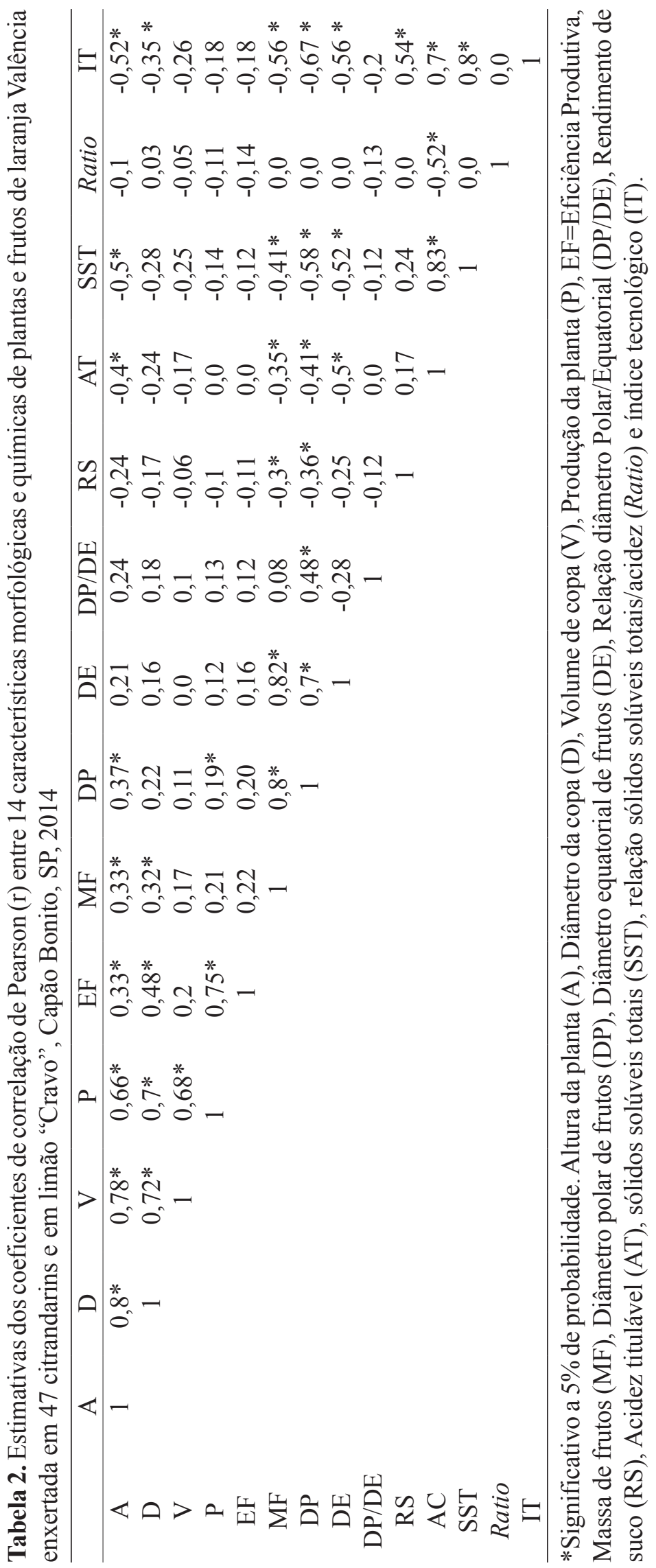




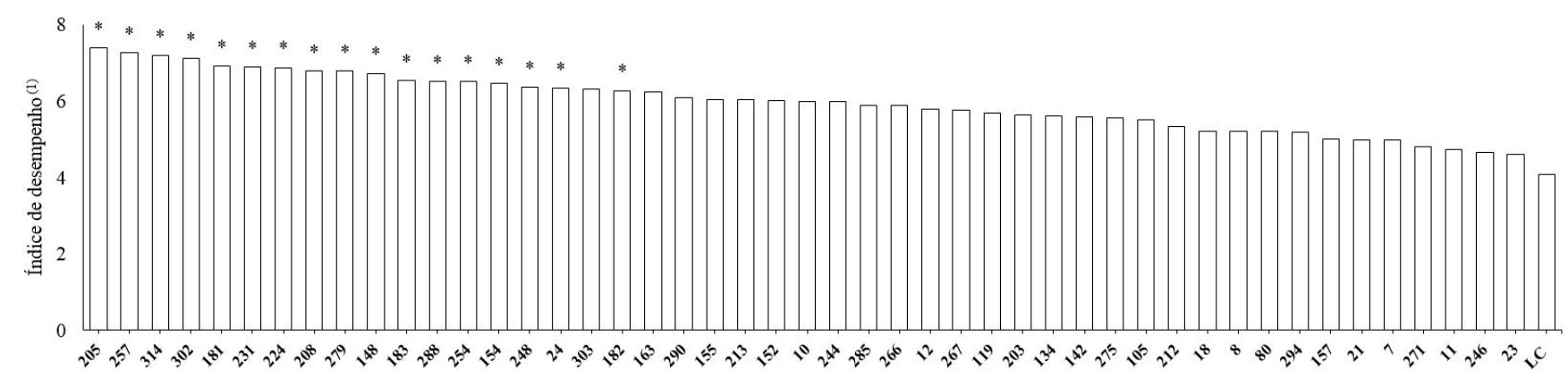

Figura 1. Índice de desempenho de 48 combinações de laranja 'Valência' com diferentes porta-enxertos. *Significativo em relação à combinação com limão ‘Cravo' (LC) pelo teste não paramétrico de Friedman a 5\% de probabilidade. ${ }^{(1)}$ Variáveis utilizadas: produção de frutos (20\%), rendimento de suco (25\%), "ratio" (40\%) e índice tecnológico (15\%).
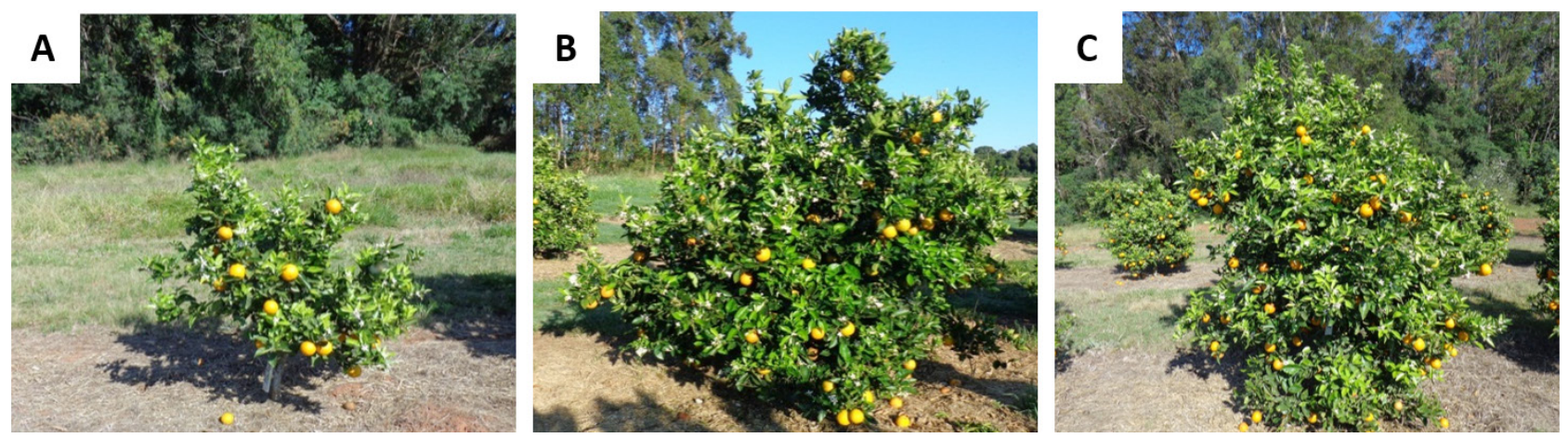

Figura 2. Combinações de laranja 'Valência' com diferentes porta-enxertos (A) TSxPT 213, (B) TSxPT 205 e (C) TSxPT257. Capão Bonito, SP, 2014.

\section{CONCLUSÕES}

Os citrandarins conferiram à laranja Valência diferenças em relação ao vigor de copa e teores de sólidos solúveis totais.

Ao menos 18 híbridos enxertados em laranja 'Valência' mostraram melhores índices de desempenho em relação ao limão 'Cravo'.

\section{REFERÊNCIAS}

Albrigo G (1992) Influências ambientais no desenvolvimento de frutos cítricos. Anais do II Seminário Internacional de Citros, Bebedouro, p. 100-105.

Andrews PK \& Marquez CS (1993) Graft incompatibility. Horticultura Review 15: 183-232.

Blumer S \& Pompeu Junior J (2005) Citrandarins como porta-enxertos para laranjeira Valência em São Paulo. Laranja. 26(2): 375-385.
Caputo MM, Mourão Filho FAA, Silva RS, Bremer Neto H, Couto HTZ \& Stuchi ES (2012). Seleção de cultivares de laranja doce de maturação precoce por índices de desempenho. Pesquisa Agropecuária Brasileira 47(11): 1669-1672.

Chitarra MFI \& Campos MAP (1981) Caracterização de alguns frutos cítricos cultivados em Minas Gerais: I. Laranjeiras doces comuns (Citrus sinensis L. Osbeck) em fase de maturação. São Paulo: CITRUS. Disponível em: <http://www.citrusbr.com/>. Acesso em 20 jul. 2017.

CITRUSBR - Associação Nacional dos Exportadores de Sucos Cítricos (2017). Disponível em: <http://www. citrusbr.com.br>. Acesso em: 17 jul 2017.

Darros-Barbosa R \& Curtolo JE (2005) Produção industrial de suco e subprodutos cítricos. In: Mattos Junior D, De Negri JD, Pio RM \& Pompeu Junior J (Eds). Citros. Campinas: Instituto Agronômico; Fundag, 2005. p. 243246, 840-870.

Di Giorgi F, Ide BY, Dib K, Marchi RJ, Triboni HDR \& Wagner RL (1990) Contribuição ao estudo do 
comportamento de algumas variedades de citros e suas implicações agroindustriais. Laranja 11(2): 567-612.

Dovale JC, Fritsche-Neto R \& Silva PSL (2011) Índice de seleção para cultivares de milho com dupla aptidão: minimilho e milho verde. Bragantia 70: 781-787.

Fadel AL (2015). Desempenho horticultural de laranjeira 'Valência' sobre onze porta-enxertos na região norte do Estado de São Paulo. Tese de Doutorado, Escola Superior de Agricultura Luiz de Queiroz, Universidade de São Paulo, Piracicaba.

Ferreira A, Cecon PR, Cruz CD, Ferrão RG, Silva MF, Fonseca AFA \& Ferrão MAG (2005) Seleção simultânea de Coffea canephora por meio da combinação de análise de fatores e índices de seleção. Pesquisa Agropecuária Brasileira 40: 1189-1195.

Ferreira DF (2008) SISVAR: um programa para análises e ensino de estatística. Revista Symposium 6(2): 36-41.

Galarça SP, Lima CSM, Silveiras G \& Rufato AR (2010) Correlação de pearson e análise de trilha identificando variáveis para caracterizar porta-enxerto de Pyrus communis L. Ciência e Agrotecnologia 34(4): 860-869.

Kimball DA (1984) Factors affecting the rate of maturation of citrus fruits. Proceedings of the XCVII Florida State Horticultural Society, Gainesville, p. 40-44.

Legua P, Bellver R, Forner J \& Forner-Giner MA (2011) Plant growth, yield and fruit quality of 'Lane Late' navel orange on four citrus rootstocks. Spanish Journal of Agricultural Research 9(1): 271-279.

Machado MA, Cristofani M, Amaral AM \& Oliveira AC (2005) Genética, melhoramento e biotecnologia de citros. In: Mattos Junior D, De Negri JD, Pio RM \& Pompeu Junior J (Eds). Citros. Campinas: Instituto Agronômico; Fundag, p. 243-246.

Medina CL, Rena AB, Siqueira DL \& Machado EC (2005) Fisiologia dos citros. In: Mattos Junior D, De Negri JD,
Pio RM, Pompeu Junior J. Citros. Campinas: Instituto Agronômico; Fundag, 2005. cap. 7, p. 148-195.

Pompeu Junior J \& Blumer S (2009) Híbridos de Trifoliata como porta-enxertos para a laranjeira 'Valência'. Pesquisa Agropecuária Brasileira 44: 701-705.

Pompeu Junior J \& Blumer S (2011) Citrandarins e outros híbridos de trifoliata como porta-enxertos para laranjeira Valência. Citrus Research \& Technology 32(3): 133-138.

Pompeu Junior J (2005) Porta-enxertos. In: Mattos Junior D, De Negri JD, Pio RM \& Pompeu Junior J (Eds). Citros. Campinas: Instituto Agronômico; Fundag, p. 63-104.

Russo G (1987). Ripening process of two orange cultivars: washington navel and navelina. Proceedings of the II International Society of Citriculture, Piracicaba, SP, p. 523-528.

Schinor EH, Cristofani-Yaly M, Bastianel M \& Machado MA(2013) Sunki Mandarin vs Poncirus trifoliata hybrids as rootstocks for pera sweet orange. The Journal of Agricultural Science 5(6): 190-200.

Scott A, Knott M (1974) Cluster-analysis method for grouping means in analysis of variance. Biometrics 30(3): 507-512.

Steger E (1990) Trinta anos de desenvolvimento em processamento de citros, histórico, estado da arte e visão geral. Laranja 11(2): 463-502.

Stuchi ES, Donadio LC \& Sempionato OR (2002) Qualidade industrial e produção de frutos de laranjeira 'Valência' enxertada sobre sete porta-enxertos. Citrus Research \& Technology 23(2): 453-470.

Stuchi ES, Sempionato OR \& Silva JAA (1996) Influência dos porta- enxertos na qualidade dos frutos cítricos. Laranja 17(1): 159-178.

Recebido: Novembro 11, 2015 Aceito: Maio 22, 2017 